\title{
Can logging in equatorial Africa affect adjacent parks?
}

\author{
$\underline{\text { Somnath Baidya Roy }}^{1}, \underline{\text { Peter D. Walsh }}^{1}$, and Jeremy W. Lichstein ${ }^{1}$
}

\begin{abstract}
Tropical deforestation can cause fundamental regional-scale shifts in vegetation structure and diversity. This is particularly true in Africa. Although national parks are being established to protect areas from deforestation and to conserve biodiversity, these parks are not immune to disturbances outside their boundaries. We used regional-scale atmospheric simulation experiments to investigate how deforestation in timber concessions might affect precipitation inside adjacent, undisturbed national parks in the equatorial African countries of Gabon and the Republic of Congo. The experiments revealed a complex response. Some parks showed rainfall reduced as much as $15 \%$, while others showed slight increases. Rainfall inside parks was particularly sensitive to upwind deforestation along the path of airborne moisture traveling inland from the ocean. A variety of shortcomings in the current modeling procedures limit the ability to extrapolate from experiments such as ours to provide spatially explicit, long-term forecasts of climate. We describe what advances in modeling are needed to produce regional-scale predictions that are robust enough to be useful to managers and policy makers.
\end{abstract}

Key Words: deforestation; logging; precipitation; climate change; Africa; tropics; national park

\section{INTRODUCTION}

Although tropical forests cover a relatively small percentage of the Earth's land surface, they hold a disproportionate share of its plant and animal species. This trove of biodiversity is now under threat from escalating deforestation (Laurance 1999, Achard et al. 2002, DeFries et al. 2002). Although deforestation affects biodiversity through a variety mechanisms (Laurance et al. 2002), one that has recently come into focus is the tendency for tropical deforestation to decrease rainfall (Costa and Foley 2000, Kanae et al. 2001, Semazzi and Song 2001, Werth and Avissar 2002). Reductions in precipitation are troubling because the plant species richness of tropical forests is strongly correlated with rainfall (Clinebell et al. 1995, Linder 2001, Taplin and Lovett 2003), and the diversity of other taxa tends to be linked to plant species richness (e. g., Andrews and O'Brien 2000). More troubling is the possibility that even moderate levels of deforestation might trigger a positive feedback loop between forest dynamics and local hydroclimatology. Studies suggest that this feedback loop could lead to drying severe enough to shift the vegetation structure from species-rich forests to relatively sparse woodlands or grasslands (Laurance and Williamson 2001, Sternberg 2001).

A feedback cycle of this kind is particularly likely in equatorial Africa, which holds $25-30 \%$ of the world's tropical forests (Roberts 1998). Along the northern border of the African forest block, the transition from forest to woodland occurs where precipitation is about 1400-1500 mm/year (Fig. 1), a level substantially higher than those typical of other tropical regions (Lieth 1975). Equatorial Africa also differs from other tropical regions in that a large proportion of its forest block experiences annual precipitation only slightly higher than the value observed at the forest-woodland transition. These facts imply that the rainfall reduction required to cause a regional-scale shift from forest to woodland may be much smaller in equatorial Africa than would be required in other major tropical forest regions. The fact that Africa has experienced several drastic reductions in forest cover in the past tens of thousands of years (Nichol 1999, Maley 2001) 
underscores the vulnerability of African forests.

The potential for regional-scale shifts of vegetation type brings into question the utility of the wildlife reserve system in equatorial Africa. It is important to ask whether simply preventing deforestation inside parks and other protected areas will be adequate to save the precious ecological communities they contain. Could deforestation outside parks cause a regional climate change that shifts the vegetation inside parks from forest to woodland or savanna?

The complexity of land-atmosphere interactions underscores the likelihood of such an event. Deforestation induces a broad suite of changes in land-surface properties that can act either competitively or synergistically to determine precipitation patterns. For example, replacing forests with grasslands reduces evapotranspiration, and, thus, there is less moisture to fall as rain. However, less evapotranspiration also acts to warm surface air, resulting in increased convection and subsequent thunderstorms. These processes are local and are important in regions in which precipitation recycling, i.e., the contribution of local evapotranspiration to precipitation, is high.

Land-cover change can also trigger remote effects (Pielke et al. 1998) over regional and even global scales. An extreme example is that of the global teleconnection between deforestation in Amazonia and precipitation in South Asia and other parts of the world (Werth and Avissar 2002). Over regional scales, Lawton et al.(2001) have shown that deforestation along the Caribbean coast affects the adjacent montane cloud forests in Costa Rica. These examples indicate that protected areas in Africa are also likely to be vulnerable to land-cover changes outside their boundaries.

Many factors, including soil, vegetation, topography, and climatology, determine the sensitivity of a regional climate to land-cover change. This dependency on region-specific characteristics makes it impossible to predict the consequences of future deforestation in Africa by simply extrapolating from the observations in Costa Rica or Amazonia. A possible solution is to conduct numerical experiments using coupled landatmosphere models that incorporate all landatmosphere interaction processes.
In this study, we used a regional climate model to investigate the first part of this problem, i.e., whether logging activity within the timber concessions in equatorial Africa can affect the climate of adjacent protected areas. Whether this change in climate can significantly affect the vegetation cover within the protected areas is an equally important part of the problem. However, we did not address this particular question in this research. Our primary aim was to direct the attention of conservationists and regional managers to the fact that protected areas are vulnerable to adverse effects from deforestation outside their boundaries.

The modeling results presented in this study are preliminary and are not designed to make long-term climatological predictions. We used the simulations only to identify the mechanism by which disturbances in the climate system travel across space. The numerical experiments also demonstrate how climate models can be used to simulate different scenarios that improve regional-level decision making.

\section{METHODS}

Rainfall in western equatorial Africa is mostly convective and confined between the Intertropical Convergence Zone (ITCZ) and the Intertropical Oceanic Confluence (IOC) (Martyn 1992). The seasonal shift in the positions of the ITCZ and the IOC determines the rainfall pattern. There are two annual dry seasons. The December-March dry season is longer and more intense in the north and east, and the June-September dry season longer and more intense in the south and west.

Our study focused on deforestation in two countries, Gabon and the Republic of Congo. These countries are of particular interest because they retain the highest proportion of original forest cover, $80 \%$ and $65 \%$ respectively, compared to other countries in the African forest block (Laporte et al. 1998). They are also home to some of the planet's most intact tropical forest communities and include the majority of the world's gorillas (Gorilla gorilla) and critical populations of common chimpanzees (Pan troglodytes) and forest elephants (Loxodonta cyclotis). The plant species richness in these forests is roughly five times higher than than those of neighboring woodlands or savannas (Linder 2001, Taplin and Lovett 2003). Furthermore, Pleistocene forest refugia with high species endemism are 
Fig. 1. Mean annual precipitation ( $\mathrm{mm}$ ) for western equatorial Africa (top) based on Wilmott and Matsuura (2000) and vegetation types in western equatorial Africa (bottom) based on Olson (1992).
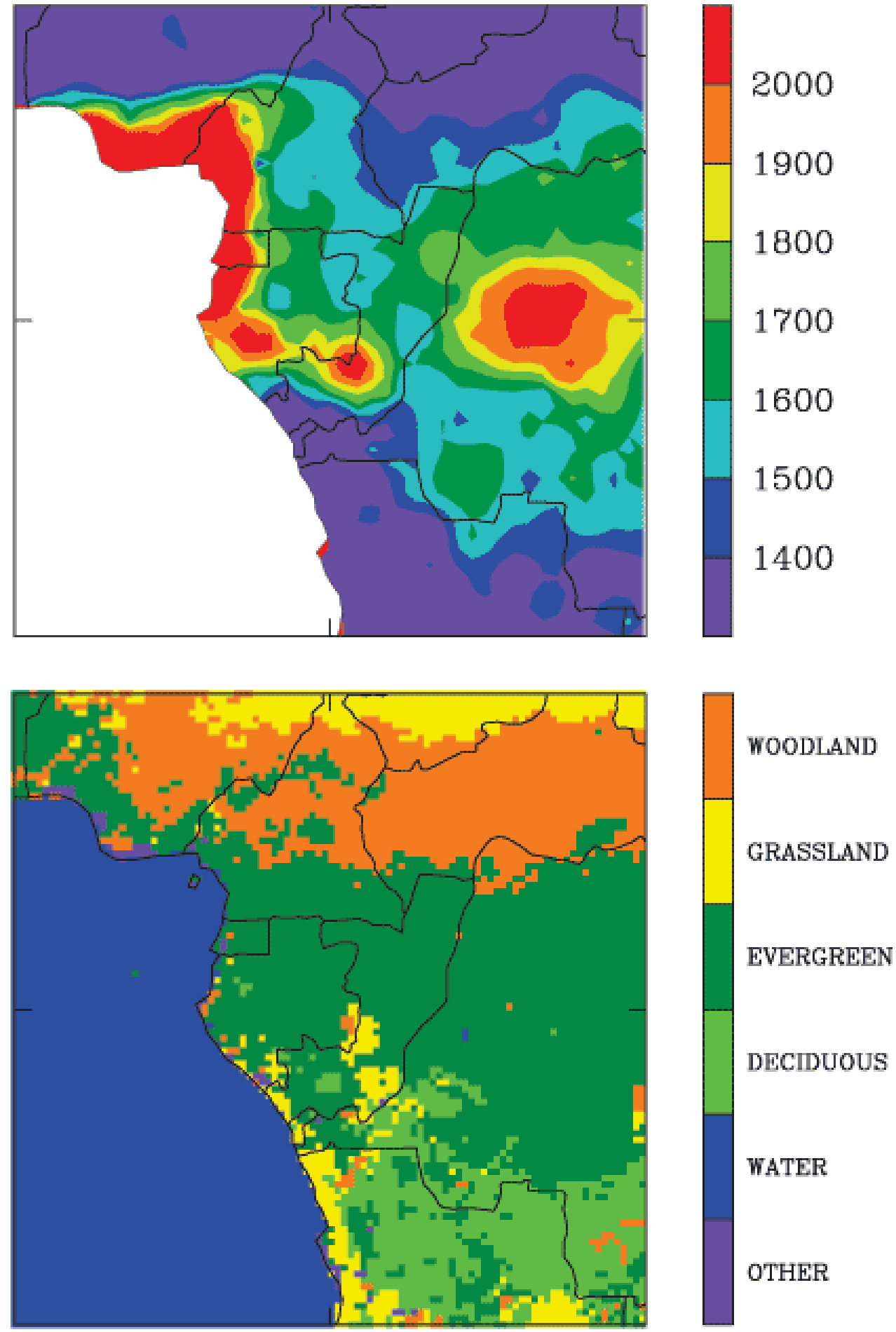
scattered throughout the two countries (Maley 2001). Although lightly inhabited by humans (Roberts 1998), Gabon and the Republic of Congo are in the midst of a logging explosion, and exports of industrial roundwood and sawnwood increased by $66 \%$ and $291 \%$, respectively, between 1990 and 2000 (FAO 2004). Much of the region has been allocated in logging concessions (Fig. 2), and logging is expected to cause substantial deforestation in the long term. If this deforestation triggers a regional-scale transition from forest to woodland or savanna, the consequences for biodiversity would be catastrophic.

We used the Regional Atmospheric Modeling System (RAMS), a mesoscale model described in detail by Pielke et al. (1992) and Cotton et al. (2002), coupled with the Land Ecosystem-Atmosphere Feedback-2 model (LEAF-2; Walko et al. 2000) to simulate the meteorology of this region for the months of January and October 2001. These two months represent typical dry and wet season conditions, respectively. The simulations modelled atmospheric and land processes over a 2500 x 2500 $\mathrm{km}$ area covering all of western equatorial Africa (Fig. 1), using a three-dimensional gird with $100 \mathrm{X}$ 100 points in the horizontal spaced $25 \mathrm{~km}$ apart. Data from the National Centers for Environmental Prediction/National Center for Atmospheric Research (NCEP/NCAR) reanalysis (Kalnay et al. 1996) were used to set the initial and boundary conditions. We used land-cover data from the Olson world ecosystems database (Olson 1992) for the two control simulations. For the deforestation experiments, the forests within known logging concessions of Gabon and the Republic of Congo were replaced with grassland (Forests Monitor 2001).

\section{RESULTS}

The simulated precipitation in the two control cases compared very well with observed precipitation climatology (Wilmott and Matsuura 2000). There were no significant differences in temperature and precipitation between the control and deforestation scenarios for January 2001, the dry season. Thus, we focused on the deforestation scenarios for October 2001. This case produced a substantial decrease in the overall rainfall pattern (Fig. 3), including a reduction of more than $10 \%$ of precipitation in some regions. The greatest reductions were generally confined to the highlands that run through the central part of the region (Fig. 4 ) and in which the precipitation is orographic.

Because local evapotranspiration is not a significant source of the precipitation in this region during this time of the year (Trenberth 1999), the change in rainfall pattern was probably caused by a deforestation-induced change in large-scale moisture transport. The precipitable water in this region is brought inland from the Atlantic Ocean by airflow from the southwest (Martyn 1992; Fig. 4). The imposed deforestation raised the surface temperature over most of the study area (Fig. 5). Although the warming was weak, it increased the intensity of turbulence, producing deeper convective cells. These circulations pushed the rainbearing clouds upward (Fig. 6). Instead of raining out over the highlands, the clouds were able to cross over to the leeward side of the highlands, which experienced a slight increase in rainfall. Lawton et al. (2001) demonstrated a similar process at work in Costa Rica. Thus, rainfall over protected areas can be strongly influenced by deforestation in regions upwind of the moisture flow.

The effect of deforestation on precipitation was not spatially uniform. Furthermore, many regions, including several protected areas, that were not deforested experienced changes in rainfall. For instance, Mwagne National Park in northeastern Gabon and Counkouati National Park in southwestern Congo showed substantial decreases in precipitation, whereas Nouabale-Ndoki National Park in northern Congo experienced a slight increase.

\section{DISCUSSION}

The strength of our modeling procedure lies in its capacity to examine how land-cover heterogeneity influences the regional-scale distribution of precipitation by integrating the competing actions of land-atmosphere interaction processes at high spatial resolutions. However, strictly speaking, these experiments were not designed to make longterm predictions, and the results should not be treated as such. This is because our simulations took into account only phenomena with spatial scales smaller than the domain size and time scales of less than one month. Processes with longer time scales, 
Fig. 2. Map of the logging concessions and protected areas in Gabon and the Republic of Congo showing (1) Nouabale-Ndoki, (2) Mwagne, and (3) Conkouati National Parks.

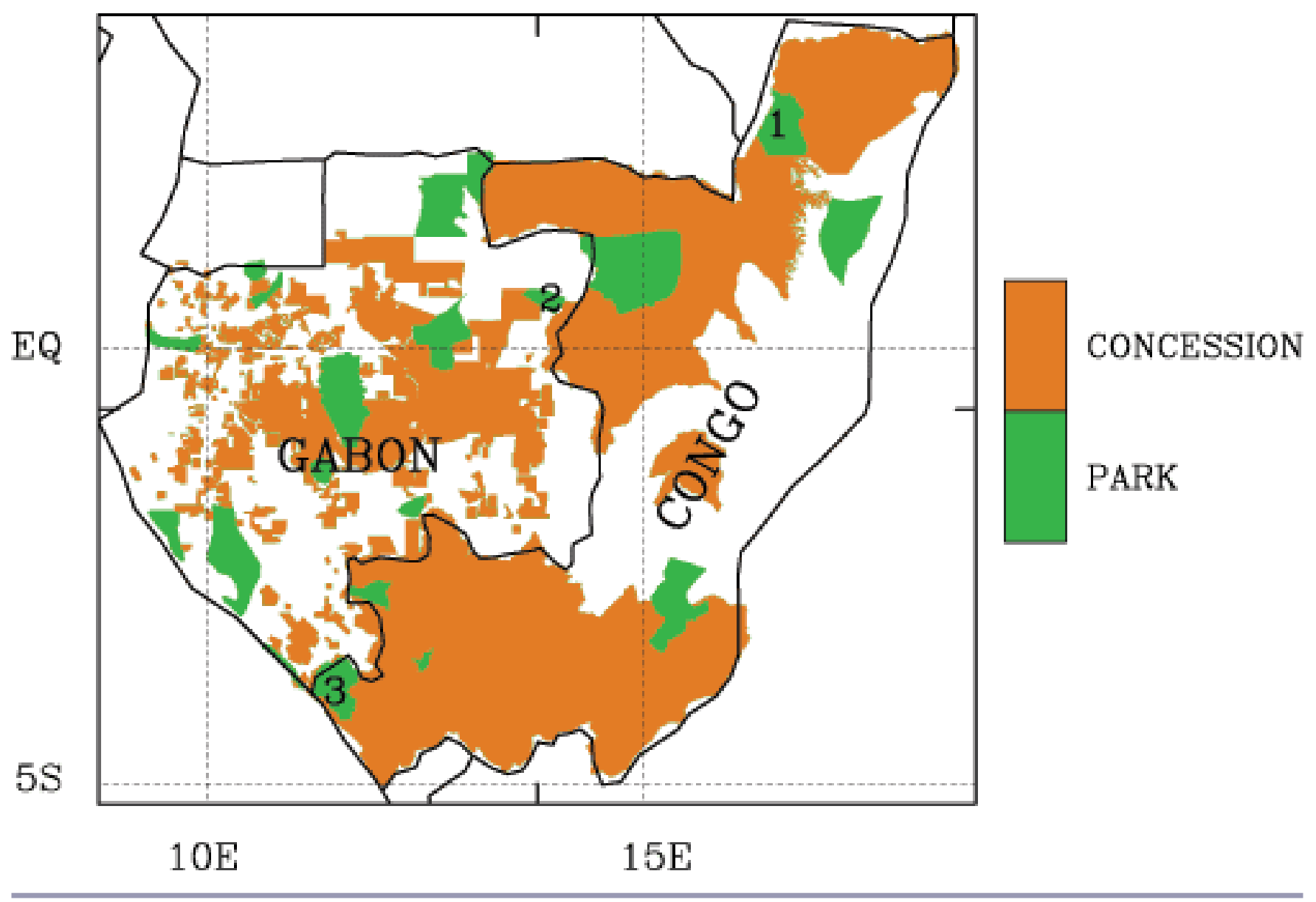

especially local land processes such as soil moisture dynamics in deep soil layers, can be important for making long-term predictions about the hydrologic cycle. Capturing these longer-term processes is not just a matter of running longer simulations because many atmospheric processes exhibit a high degree of correlation between spatial and temporal scales, e.g., small thunderstorms last less than an hour, whereas large hurricanes can thrive for days. Thus, larger simulation domains would also be required, and the computational cost would go up geometrically.

In principle, this issue could be addressed by using a General Circulation Model (GCM) instead of a regional model. GCMs are not constrained by domain size because they span the entire earth and can be run for years. These have been used for studying hypothetical large-scale scenarios such as the impact of deforesting the entire Congo (Semazzi and Song 2001) or the Amazon (Werth and Avissar 2002) regions. However, GCMs are poorly suited for our purpose because their responses to smallscale surface perturbations are usually masked by model noise. Additionally, the spatial resolutions of GCMs (2-3 $3^{\circ}$ latitude and longitude or $200-300 \mathrm{~km}$ near the equator) are too coarse to resolve realistic fine-scale features like the parks and timber concession maps used in this study. Because many GCM parameterizations are highly scaledependent, running GCMs at resolutions high enough to resolve the logging concessions would require not only bigger and faster computers but also new parameterization schemes. 
Fig. 3. Simulated precipitation difference $(\mathrm{mm})$ between control and deforestation scenarios for October 2001 in Gabon and the Republic of Congo.
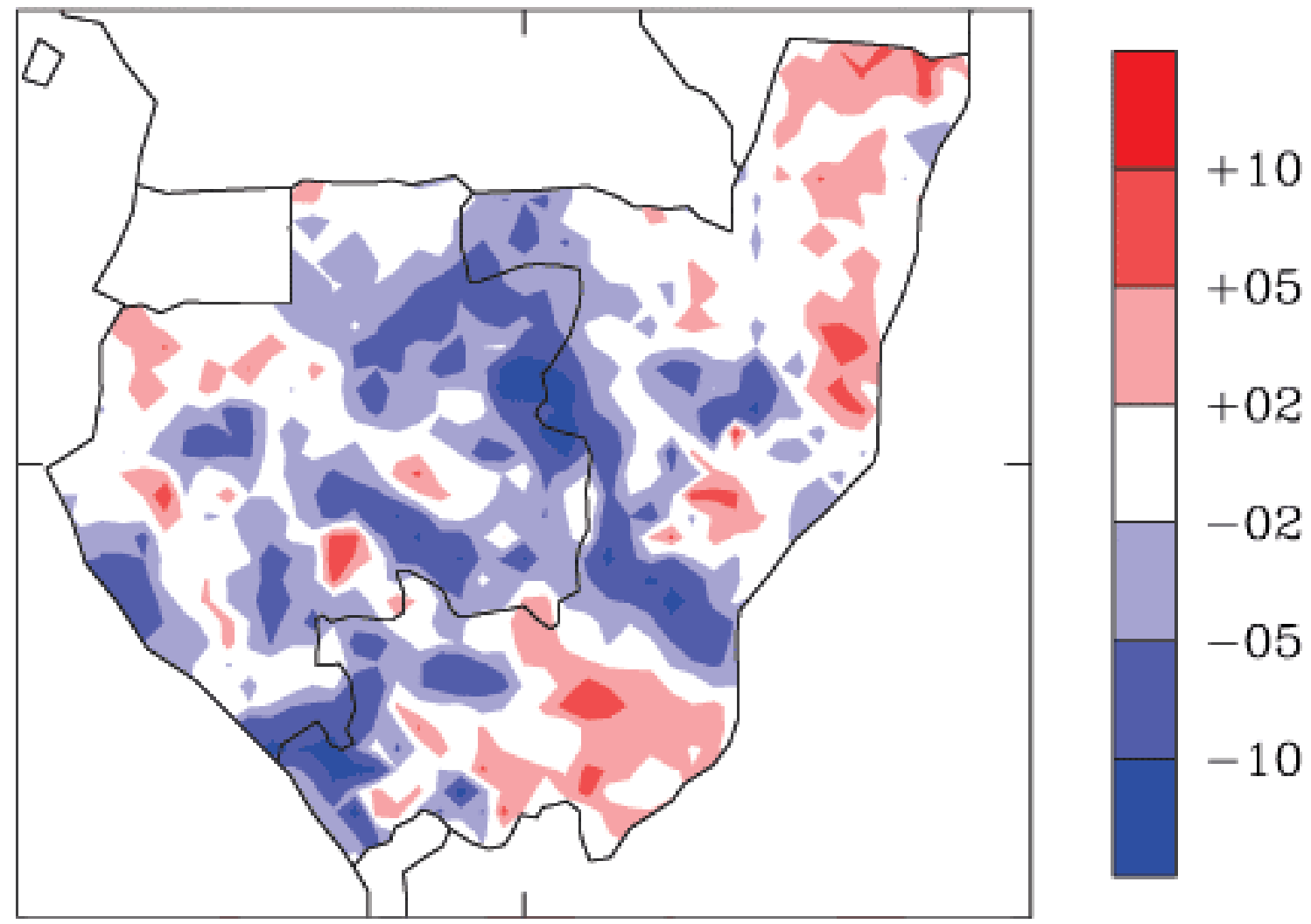

A further issue is the dynamic nature of land-cover change. In this work, we have followed the traditional approach of seeking an equilibrium atmospheric response to a stationary perturbation in the land cover. However, timber extraction is a timeevolving process, and the ecosystem response is also gradual. For instance, at the edges of logged areas, increased penetration by sun can dry the soil and the understory, increasing the susceptibility to forest fires (Nepstad et al. 1999). Colonization after fire is then dominated by young or shallow-rooted plants, e.g., grasses, with lower dry season transpiration rates than those of adult trees. These properties can lead to less convective rainfall and a drier topsoil that further increases the probability of fires and the predominance of grasses over woody species (Laurance and Williamson 2001, Sternberg 2001). The static treatment of vegetation in our simulations did not address these potentially very important sources of feedback at all.

It is also important to analyze the statistical significance of the results. Because of the chaotic nature of the climate system, small differences in the initial conditions can lead to drastically different end points. The difference between the control and deforested scenarios results in part from this internal variability of the climate system and in part from that change in land cover. The relative contribution of these two factors in the experiment needs to be estimated. The only way to handle this problem is to conduct a series of simulations with different initial conditions and use statistical tests to evaluate the significance of the differences between the ensemble-averaged outputs. Standard tests like the $t$ test have to be extensively modified to account for the fact that meteorological variables are highly correlated in space and time and do not follow 
Fig. 4. Topography (m) for Gabon and the Republic of Congo. The dark arrow shows the general direction of the path of moist airflow from the Atlantic Ocean.
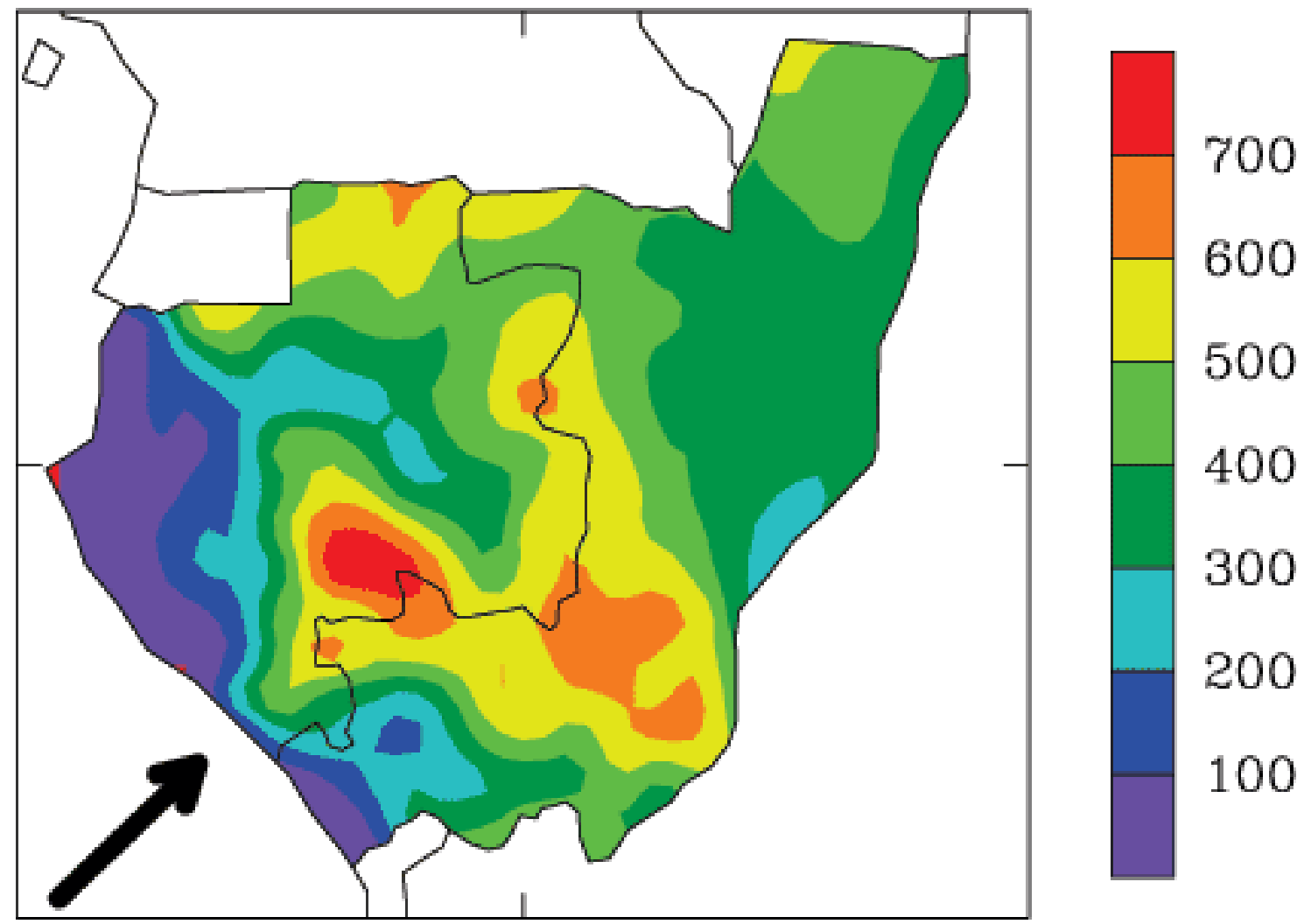

known statistical distributions (von Storch and Zwiers 2002). In this context, it is worth pointing out that conducting an ensemble of simulations with a regional climate model is computationally very expensive.

An ideal approach to addressing these issues would be to conduct an ensemble of long-term simulations with a GCM that included both estimates of future deforestation rates and vegetation dynamics. To account for small-scale land-cover changes such as those expected in our study area, a regional-scale model should be nested within the GCM to combine spatial explicitness with long-term predictability. Further realism could be added by including globalscale phenomena such as land-cover changes in other regions or increases in greenhouse gases.

This model can be used to simulate different deforestation scenarios. For example, this study and the work of Lawton et al. (2001) suggest that protected areas are vulnerable to deforestation in regions upwind of moisture flow. Thus, it would be interesting to investigate if eliminating or reducing logging intensity in concessions on the western slope of the highlands would reduce the impact on precipitation.

Although many of these techniques have already been applied to study specific questions, some are still in the experimental stage. The challenge is to put all of these together into a comprehensive modeling strategy that can yield predictions on a temporal and spatial scale useful to managers and policy makers. Obviously, this will require state-ofthe-art computing facilities, which, unfortunately, are not readily available to conservation biologists. 
Fig. 5. Simulated monthly averaged near-surface air temperature differences $(\mathrm{K})$ between control and deforestation scenarios for October 2001 in Gabon and the Republic of Congo.
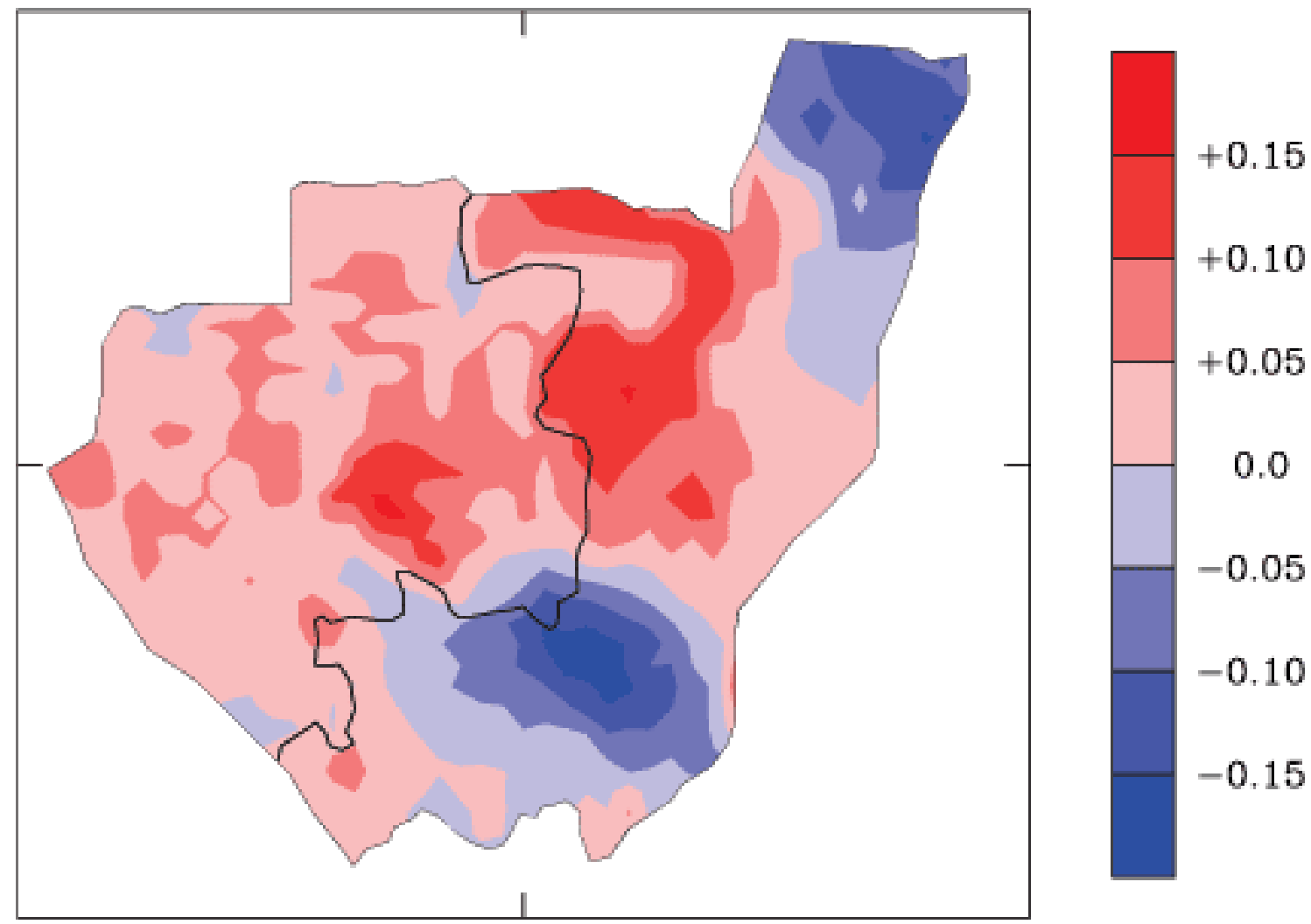

\section{CONCLUSION}

Our simulations suggest that extensive logging in the timber concessions in western equatorial Africa could affect the rainfall in adjacent national parks and other protected areas. The magnitude of rainfall reduction seen in the simulations is large enough to shift the vegetation of some parks across the transition from forest to woodland or savanna with a consequent crash in biodiversity. Protecting the national parks from extensive deforestation is not enough. At the very least, we also need to protect forests along the path that moisture travels inland from the ocean to the parks.

It is therefore important to assess the potential impact of logging on the regional climate as a whole. Regional climate models that incorporate both local and nonlocal meteorological phenomena are effective tools that can be used to simulate different deforestation scenarios. With modest technical improvements and ever-improving computing resources, these models could, in the near future, provide useful information for developing sensible regional land-use policies that meet both economic and environmental needs. The modeling results presented this paper offer a flavor of this possibility.

Responses to this article can be read online at: http://www.ecologyandsociety.org/vollo/iss 1/art6/responses/

\section{LITERATURE CITED}

Achard, F., H. D. Eva, H. J. Stibig, P. Mayaux, J. Gallego, T. Richards, and J. P. Malingreau. 2002. Determination of deforestation rates of the world's humid tropical forests. Science 297:999-1002. 
Fig. 6. Simulated monthly averaged cloud-base-height differences (m) between control and deforestation scenarios for October 2001 in Gabon and the Republic of Congo.
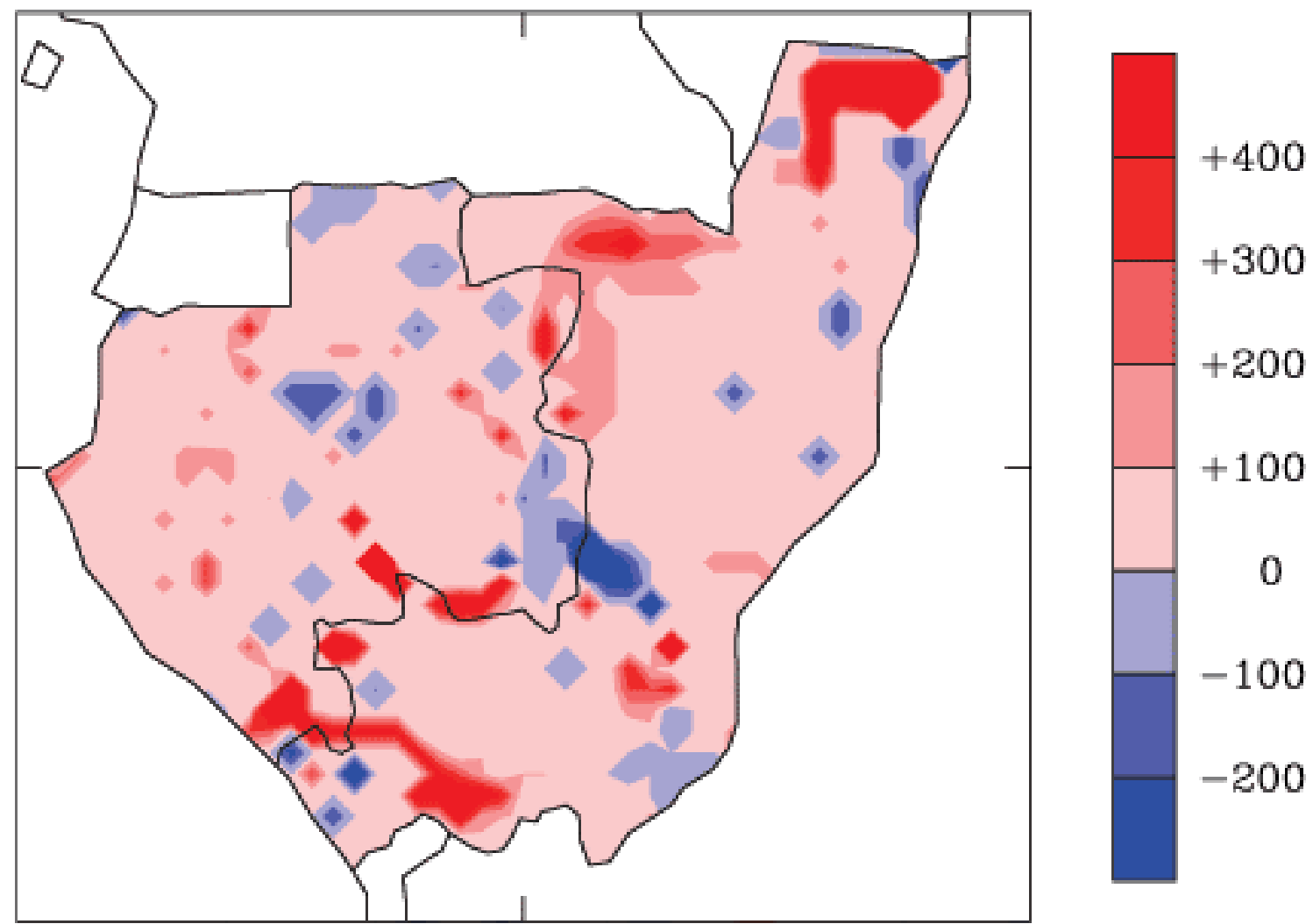

Andrews, P., and E. M. O'Brien. 2000. Climate, vegetation, and predictable gradients in mammal species richness in southern Africa. Journal of Zoology

251:205-231.

Clinebell, R. R., O. L. Phillips, A. H. Gentry, N. Stark, and H. Zuuring. 1995. Prediction of neotropical tree and liana species richness from soil and climatic data. Biodiversity and Conservation 4:56-90.

Costa, M. H., and J.A. Foley. 2000. Combined effects of deforestation and doubled atmospheric $\mathrm{CO}_{2}$ concentrations on the climate of Amazonia. Journal of Climate 13:18-34.

Cotton, W. R., R. A. Pielke, R. L. Walko, G. E. Liston, C. J. Tremback, H. Jiang, R. L. McAnelly, J. Y. Harrington, M. E. Nicholls, G. G. Carrio, and J. P. McFadden. 2003. RAMS 2001: current status and future directions. Meteorology and Atmospheric Physics 82:5-29.

DeFries, R. S., R. A. Houghton, M. C. Hansen, C. B. Field, D. Skole, and J. Townshend. 2002. Carbon emissions from tropical deforestation and regrowth based on satellite observations for the 1980s and 1990s. Proceedings of the National Academy of Sciences 99:14256-14261.

FAO. 2004. FAOSTAT data. Available online at: http://apps.fao.org/faostat/form?collection=Forestry. Primary\&Domain=Forestry\&servlet $=1 \&$ hasbulk $=-$ 0 \&version $=$ ext $\&$ language $=\mathrm{EN}]$.

Forests Monitor. 2001. Sold down the river. The need to control transnational forestry corporations: a European case study. Forests Monitor, Cambridge, UK. Available online at http://www.forestsmonitor.org/reports/solddownriver/ 
cover.htm.

Kanae, S., T. Oki, and K. Musiake. 2001. Impact of deforestation on regional precipitation over the Indochina peninsula. Journal of Hydrometeorology 2:51-70.

Kalnay, E., M. Kanamitsu, R. Kistler, W. Collins, D. Deaven, L. Gandin, M. Iredell, S. Saha, G. White, J. Woollen, Y. Zhu, M. Chelliah, W. Ebisuzaki, W. Higgins, J. Janowiak, K. C. Mo, C. Ropelewski, J. Wang, A. Leetma, R. Reynolds, R. Jenne, and D. Joseph. 1996. The NCEP/NCAR 40-year reanalysis project. Bulletin of the American Meteorolological Society 77:437-471.

Laporte, N., S. J. Goetz, M. Heinicke, and C. O. Justice. 1998. A new land cover map of central Africa derived from multiresolution, multitemporal satellite observations. International Journal of Remote Sensing 18:3537-3550.

Laurance, W. F. 1999. Reflections on the tropical deforestation crisis. Biological Conservation 91:109-117.

Laurance, W. F., and G. B. Williamson. 2001. Positive feedbacks among forest fragmentation, drought, and climate change in the Amazon. Conservation Biology 15:1529-1535.

Laurance, W. F., T. E. Lovejoy, H. L. Vasconcelos, E. M. Bruna, R. K. Didham, P. C. Stouffer, C. Gascon, R. O. Bierregaard, S. G. Laurance, and E. Sampaio. 2002. Ecosystem decay of Amazonian forest fragments: a 22-year investigation. Conservation Biology 16:605-618.

Lawton, R. O., U.S. Nair, R. A. Pielke, and R. M. Welch. 2001. Climatic impact of tropical lowland deforestation on nearby montane cloud forests. Science 294:584-587.

Lieth, H. 1975. Modelling the primary productivity of the world. Pages 233-263 in H. Lieth and R. H. Whittaker, editors. Primary productivity of the biosphere. Springer-Verlag, New York, New York, USA.

Linder, H. P. 2001. Plant diversity and endemism in sub-Saharan tropical Africa. Journal of Biogeography 28:169-182.
Maley, J. 2001. The impact of arid phases on the African rain forest through geological history. Pages 69-87 in W. Weber, L. J. T. White, A. Vedder, and L. Naughton-Treves, editors. African rainforest ecology and conservation. Yale University Press, New Haven, Connecticut, USA.

Martyn, D. 1992. Climates of the world. Developments in atmospheric science 18. Elsevier, New York, New York, USA.

Nepstad, D. C., A. Verissimo, A. Alencar, C. Nobre, E. Lima, P. Lefebvre, P. Schlesinger, C. Potter, P. Moutinho, E. Mendoza, M. Cochrane, and V. Brooks 1999. Large-scale impoverishment of Amazonian forests by logging and fire. Nature 398:505-508.

Nichol, J. E. 1999. Geomorphological evidence and Pleistocene refugia in Africa. The Geographical Journal 165:79-89.

Olson, J. S. 1992. World ecosystems (WE1.4). Digital raster data on a 10-minute Cartesian orthonormal geodetic $1080 \times 2160$ grid. National Geophysical Data Center, Boulder, Colorado, USA. Available online at

http://www.ngdc.noaa.gov/seg/cdroms/ged iia/datasets/ a05/ow.htm.

Pielke, R. A., W. R. Cotton, R. L. Walko, C. J. Tremback, M. E. Nicholls, M. D. Moran, D. A. Wesley, T. J. Lee, and J. H. Copeland. 1992. A comprehensive meteorological modeling systemRAMS. Meteorology and Atmospheric Physics 49:69-91.

Pielke, R. A., R. Avissar, M. Raupach, A. J. Dolmann, X. Zeng, and A. S. Denning. 1998. Interactions between the atmosphere and terrestrial ecosystems: influence on weather and climate. Global Change Biology 4:461-475

Roberts, L. 1998. World resources 1998-99: environmental change and human health. Oxford University Press, New York, New York, USA. Available online at

http://pubs.wri.org/pubs description.cfm?PubID=2889

Semazzi, F. H. M., and Y. Song. 2001. A GCM study of climate change induced by deforestation in Africa. Climate Research 17:169-182. 
Taplin, J. R. D., and J. C. Lovett. 2003. Can we predict centres of plant species richness and rarity from environmental variables in sub-Saharan Africa? Botanical Journal of the Linnean Society 142:187-197.

Trenberth, K. E. 1999. Atmospheric moisture recycling: role of advection and local evaporation. Journal of Climate 12:1368-1381.

von Storch, H., and F. W. Zwiers. 2002. Statistical analysis in climate research. Cambridge University Press, Cambridge, UK.

Walko, R. L., L. E. Band, J. Barron, T. G. F. Kittel, R. Lammers, T. J. Lee, D. Ojima, R. A. Pielke, C. Taylor, C. Tague, C. J. Tremback, and P. L. Vidale. 2000. Coupled atmosphere-biophysicshydrology model for environmental modeling. Journal of Applied Meteorology 39:931-944.

Werth, D., and R. Avissar. 2002. The local and global effects of Amazon deforestation. Journal of Geophysical Research

107 (D20) 8087, doi:10.1029/2001JD000717.

Willmott, C., and K. Matsuura. 2000. 47-year time series of gridded monthly temperature, precipitation, and water budget variables. Center for Climatic Research, University of Delaware, Newark, Delaware, USA. Available online at http://www.cdc.noaa.gov/cdc/data.UDel AirT Precip. $\underline{\text { html. }}$ 